\title{
Epistemic stance marking in spoken Danish
}

\author{
JANUS MORTENSEN
}

This article is concerned with the pragmatic functions and social meaning of epistemic stance marking in Danish. Drawing on Kasper Boye's notion of epistemic meaning, Peter White's notion of dialogic space and John Du Bois' notion of the stance triangle, the article argues that speakers use epistemic expressions to specify various types and degrees of support for the propositions they put forward, and thereby either open or close the dialogic space of the unfolding interaction. In doing so, speakers position themselves vis-à-vis their propositions and their interlocutors and display various types of alignment. This process is referred to as epistemic stance marking ('epistemisk positionering' in Danish). By focussing on naturally occurring interaction, the article aims to make a contribution to the understanding of epistemic expressions in Danish, particularly their meaning in spoken interaction. It is argued that the basic cognitive meaning of epistemic expressions that has been identified by Boye and others is not sufficient if we want to understand the use of epistemic expressions in spoken interaction. The article shows that in such contexts, epistemic expressions also play an important social role in organizing the dialogic space and facilitating the management of interpersonal relations. 